\title{
PEMBINAAN USAHA PEMBUATAN PRODUK KREATIF DI DUSUN IV DESA PAYA PASIR TEBING SYAHBANDAR
}

\author{
Khafi Puddin $^{1 *}$, Mesra ${ }^{2}$, Kornelius Harefa ${ }^{1}$ \\ ${ }^{1}$ Fakultas Ekonomi Universitas Negeri Medan, Medan, Indonesia \\ ${ }^{2}$ Fakultas Bahasa dan Sastra Universitas Negeri Medan, Medan, Indonesia \\ *Penulis Korespondensi: afif se77@yahoo.com
}

\begin{abstract}
Abstrak
Tujuan kegiatan IbM ini adalah memberikan solusi atas permasalahan yang dihadpi mitra dalam mengembangkan usahanya baik aspek produksi dan manajemen usaha melalui proses penyuluhan, pelatihan dan pendampingan guna meningkatan pengetahuan dan keterampilan mitra dalam mengelola limbah kayu dan triplek bekas bongkaran konstruksi bangunan menjadi produk kretif bernilai ekonomis tinggi yang jelas pangsa pasarnya. Target khusus dalam kegiatan IbM ini adalah meningkatkan pendapatan/kesejahteraan mitra melalui penerapan strategi diversifikasi produk yang berorientasi pada aspek pemasaran dan manajemen pengelolaan usaha mitra. Luaran yang dihasilkan dari kegiatan ini berupa 1) Produk kreatif (Permainan edukatif, lampion hias dan rumah barbie), yang jelas pangsa pasarnya 2) Mesin listrik pemotong kayu yang dapat menunjang perbaikan kualitas produk mitra, 3) Pangsa pasar baru untuk produk yang dihasilkan mitra 4) Laporan Keuangan/Pembukuan untuk usaha kecil yang dapat digunakan untuk memantau perkembangan usaha mitra; dan 5) Karya ilmiah yang akan diterbitkan di jurnal LPM Unimed. Metode pendekatan yang digunakan untuk mencapai tujuan kegitan IbM adalah optimalisasi pemanfaatan limbah triplek dan kayu bekas konstruksi bangunan dan manajemen pengelolaan UMKM, serta metode pelaksanaannya meliputi: penyuluhan, pelatihan produksi, pelatihan manajemen usaha, dan pendampingan. Kegiatan ini dilaksanakan di desa paya pasir kecamatan tebing syahbandar kabupaten serdang bedagai berjarak kurang lebih $58 \mathrm{~km}$ dari Universitas Negeri Medan. Di desa tersebut terdapat kelompok masyarakat yang memiliki usaha memproduksi lemari pakaian, kandang ayam, dan meja sekolah yang bahan bakunya limbah kayu dan triplek bekas bongkaran konstruksi bangunan. dan berkeinginan untuk mengembangkan usahanya/ meningkatkan pendapatannya.
\end{abstract}

Kata Kunci: Produk Kreatif, Limbah triplek, Rumah Barbie

\begin{abstract}
The purpose of this activity is to provide solutions to the problems faced by partners in developing their business in both production and business management aspects through the extension, training and mentoring process in order to increase the knowledge and skills of partners in managing wood waste and plywood building construction disbursement into high value economic creami product a clear market share. The specific target in this IbM activity is to increase the income / welfare of partners through the implementation of product diversification strategy that is oriented on marketing aspect and management of partner business management. The output generated from this activity is 1) Creative products (Educative games, decorative lanterns and barbie houses), clear market share 2) Wood cutting machine that can support the quality improvement of partner products, 3) New market share for partner-generated products 4) Financial Reports / Bookkeeping for small business that can be used to monitor the development of partner's business; and 5) Scientific works to be published in LPM Unimed journals. The approach method used to achieve IbM's goal is optimizing the utilization of waste of wood plywood and the former of building construction and management of UMKM management, and its implementation methods include: counseling, production training, business management training, and mentoring. This activity is carried out in the village of sand dune cliffs syahbandar district serdang bedagai is approximately $58 \mathrm{~km}$ from Medan State University. In the village there are community groups that have businesses producing wardrobe, chicken coops, and school desks that raw materials waste wood and plywood dismantling building construction. and wish to expand its business / increase its income.
\end{abstract}

Keywords: Creative Product, Waste plywood, Barbie House 


\section{PENDAHULUAN}

\subsection{Analisis Situasi}

Desa Paya Pasir merupakan desa yang terletak di kecamatan tebing syahbandar kabupaten serdang bedagai, yang jaraknya $58 \mathrm{Km}$ dari Universitas negeri Medan; dan berjarak $20 \mathrm{Km}$ dari kota tebing tinggi didaerah ini mulai marak atau tumbuh bisnis properti (Perumahan dan Ruko khususnya di sepanjang jalan utama tebing tinggi kisaran dan sekitarnya ;memiliki potensi menghasilkan limbah kayu dan triplek bongkaran konstruksi beton yang jumlahnya cukup banyak dan belum dioptimalkan pemanfaatannya. Oleh pengembang biasanya triplek bekas cor-coran beton ini di jual dengan harga yang sangat murah (borongan Rp. 400.000,/colt diesel) setelah beberapa kali pakai, padahal limbah kayu dan triplek ini masih dapat ditingkatkan nilainya dengan memanfaatkannya menjadi produk kreatif berupa permainan edukatif, lapion hias, rumah barbie dll yang bernilai jual tinggi dan jelas pangsa pasarnya.

Sementara itu bagi masyarakat di dusun IV desa paya pasir kecamatan tebing syahbandar kabupaten serdang bedagai, terdapat beberapa keluarga (Bapak Jamaluddin Purba dan Ahmad Fathoni) memiliki usaha skala rumahan memproduksi lemari pakaian (ukuran Lebar 1m x Panjang 2m), kandang burung yang bahan bakunya sudah memanfaatkan limbah triplek bekas konstruksi beton dan juga menerima pesanan pembuatan steling warung, meja sekolah yang skala produksinya sangat terbatas, rata-rata penjualan/ Omzet rata-rata Rp. 6000.000/Bln) dengan keuntungan kotor maksimal 60\% (3.600.000,/bln) dirasa sangat tidak cukup untuk memenuhi kebutuhan keluarga; dikarenakan mereka masih harus mengupah tenaga kerja Rp. 600.000/orang dan membeli material pendukung seperti paku, engsel, amplas, dempul kayu dan cat pernis; apalagi produksi sering bergantung pada pesanan konsumen, tidak jarang hasil produksi mereka menumpuk lama sebelum laku dijual.

Bahan baku triplek dan beroti yang mereka gunakan adalah sisa atau limbah dari bongkaran bangunan (Konstruksi beton) dengan ukuran lebar $4 \mathrm{~cm}$ dan panjang 8 meter dengan ketebalan triplek 5 s.d 10 mm di peroleh dengan cara membeli dari masyarakat maupun perusahaan properti/ pengembang yang ada disekitar mereka tinggal (biasanya dibeli dengan cara borongan;) dengan harga relatif murah (Rp 400.000,/truk) tak jarang mereka mendapatkan bahan baku limbah triplek dan potongan broti dari luar daerah yang dekat dengan lokasi mitra. Kualitas bahan baku bervariasi, karena triplek berasal dari limbah bangunan, sebelum digunakan mitra harus memilih triplek yang masih layak digunakan dan memisahkan triplek yang tidak layak digunakan. Untuk triplek yang layak digunakan kembali; sebelum dijadikan bahan baku; mitra harus membersihkan dahulu dari unsur semen yang masih menempel dengan cara mengamplasnya dan mendempul triplek yang berlubang karena paku, ataupun retak akibat dari proses pembongkaran untuk selanjutnya di buat menjadi lemari pakaian, meja sekolah (tergantung pesanan), kandang burung dan produk lainnya.

Tenaga Kerja yang terlibat dalam usaha mitra berjumlah 5 orang, 3 orang bekerja dengan mitra 1 bapak Jamaluddin purba dan 2 orang bekerja dengan mitra 2 bapak Ahmad Fathoni, mereka mendapatkan upah berdasarkan output yang dihasilkan; misal; untuk 1 unit lemari yang selesai dikerjakan mereka mendapat upah Rp. 50.000,- rata-rata upah yang diperoleh para pekerja dalam satu bulan berkisar antara Rp.600.000, s,d Rp.800.000,- dan dianggap masih kurang (dibawah rata rata UMP)

Pemasaran dilakukan secara konvensional, artinya mitra selama ini hanya menunggu pesanan datang; ada juga masyarakat yang membantu pemasarannya dengan menjajakannya ke daerah sekitar mitra dengan berkeliling kampung atau perumahan menggunakan sarana transportasi sepeda motor yang kadang kadang belum tentu laku terjual dalam sehari.

Mitra berkeinginan untuk meningkatkan kapasitas produksinya agar omzet dapat ditingkatkan sehingga kesejahteraan mereka meningkat, untuk itu tim pengusul bersama mitra sepakat untuk bekerjasama mencari solusi atas permasalahan tersebut; dan disepakati mitra akan diberi pendidikan, pelatihan serta pendampingan bidang pemasaran dan mitra akan dilatih untuk memproduksi produk kreatif (mainan edukatif, lampu hias, rumah barbie dan produk kreatif yang bernilai ekonomis tinggi dan jelas pangsa pasarnya. Diharapkan melalui kegiatan IbM ini nantinya mitra akan memiliki kemampuan dalam mendiversifikasi hasil produksinya dan juga memiliki kemampuan dalam memasarkannya.

Peralatan yang digunakan mitra hanya perlatan sederhana seperti gergaji tangan, ketam tangan, palu, pahat kayu dan lain lain; mitra berkeinginan untuk memiliki gergaji listrik untuk memudahkan proses produksi dan mendapatkan hasil potongan yang lebih baik.

Pengembangan usaha mitra dari tahun ketahun stagnan, hal ini disebabkan adanya keterbatasan pengetahuan dalam berwirausaha dan juga adanya keterbatasan modal, selama ini keuntungan yang mitra peroleh hanya cukup untuk memenuhi kebutuhan dasar (belanja kebutuhan dapur ).

Mitra sangat berkeinginan untuk dibantu mengembangkan usahanya dengan fokus pada optimalisasi pemanfaatan limbah triplek dan beroti bekas konstruksi bangunan untuk lebih dapat ditingkatkan nilainya menjadi aneka produk kreatif yang jelas pangsa pasarnya sehingga berdampak pada peningkatan pendapatan dan kesejahteraannya. 
Mengingat cukup besarnya potensi ekonomi dari usaha yang dillakukan oleh Mitra dalam kegiatan Ibm ini dan di dukung dengan keberadaan bahan baku yang cukup banyak; apalagi murah dan mudah untuk mendapatkannya; peluang pasar masih terbuka lebar untuk produk kreatif yang akan dihasilkannya; maka untuk itu diperlukan satu upaya untuk memberdayakannya.

Kondisi inilah yang membuat tim pengusul merasa perlu untuk membantu mitra dalam mencari solusi atas permasalahan yang dihadapi mitra baik dari aspek produksi dan manajemen usaha dan diharapkan pada akhirya akan berdampak pada peningkatan pendapatan dan kesejahteraan mitra.

Perguruan Tinggi yang merupakan sentral ilmu pegetahuan, yang menjalankan perannya sebagai pelayan mahasiswa dan masyarakat, telah membantu mitra dalam upaya mengembangkan usahanya agar menjadi lebih baik dari sebelumnya

\section{SOLUSI DAN TARGET LUARAN}

\subsection{Solusi Yang Ditawarkan}

Berdasarkan permasalahan yang di temukan, maka solusi dan target luaran dalam kegiatan IbM ini adalah sebagai berikut:

\section{a. Aspek Produksi}

Solusi untuk masalah optimalisai pemanfaatan limbah triplek dan kayu bekas konstruksi bangunan, telah diberi pelatihan serta pendampingan pembuatan produk kreatif berupa aneka permainan edukatif, lampu hias berbahan triplek dan mainan anak berupa rumah barbie yang jelas pangsa pasarnya dan memiliki nilai ekonomis yang tinggi. Dengan luaran sesuai dengan yang sebagai berikut:

\section{Luaran dan Spesifikasi}

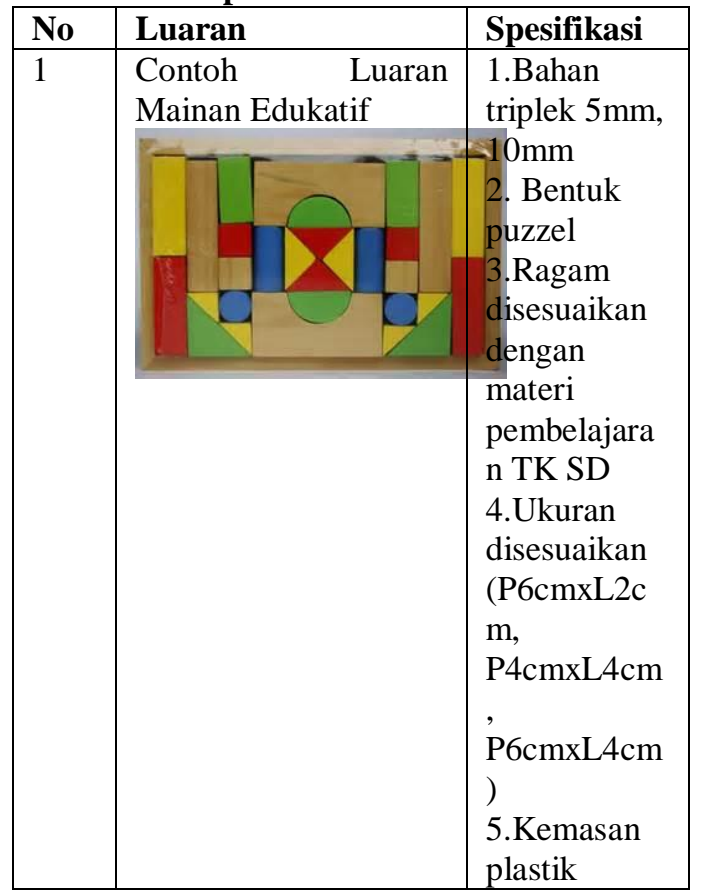

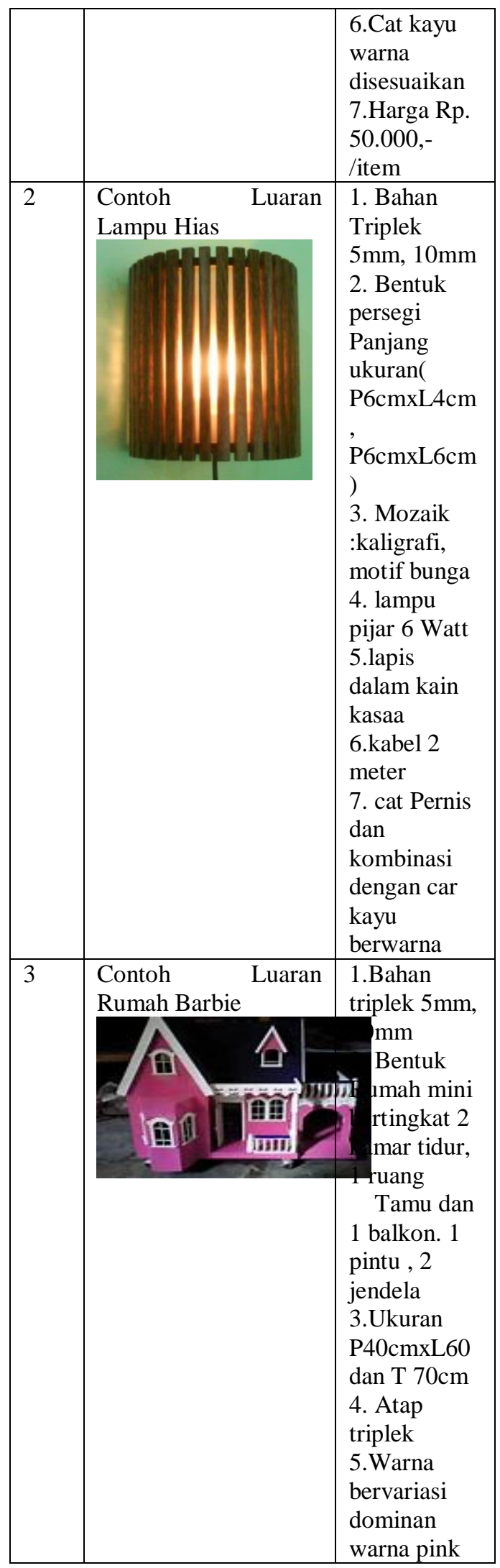

Solusi untuk masalah peralatan produksi, mitra telah diberi peralatan berupa mesin potong triplek dan perlatan pendukung lain yang diperlukan untuk memudahkan proses produksi dan memperoleh hasil/kualitas yang lebih baik. 
Dengan luaran dan spesifikasi yang akan dihasilkan sebagai berikut:

\begin{tabular}{|c|c|c|}
\hline No & Luaran & Spesifikasi \\
\hline 1 & Mesin Potong Kayu & $\begin{array}{l}\text { Capacity at } \\
\text { o dgrees } \\
66 \mathrm{~mm} \\
\text { Confinuos } \\
\text { rating } \\
1.050 \mathrm{w} \\
\text { Input } \\
\text { Wheel } \\
\text { diameter } \\
185 \mathrm{~mm} \\
\text { Dimension } \\
\text { (LxWxH) } \\
28 \\
\mathrm{x} 243 \mathrm{~mm} \\
\text { Net } \\
\text { Weight } 3,7 \\
\text { kg } \\
\text { Power } \\
\text { Suplay } 2.0 \\
\text { Voltage } \\
220 \text { v / } 110 \\
\text { v }\end{array}$ \\
\hline
\end{tabular}

\section{b. Aspek Manajemen Usaha}

1. Solusi untuk masalah pemasaran/ Perluasan pangsa pasar, mitra akan diberi pendidikan serta pendampingan dalam memasarkan setiap produk yang dihasilkannya. Dengan luaran dan spesifikasi yang dihasilkan sesuai dengan yang direncanakan sebagai berikut:

\begin{tabular}{|l|l|l|}
\hline No & Luaran & Spesifikasi \\
\hline 1 & Pangsa & Sekolah TK/PAUD \\
& Pasar Baru & Sekolah Dasar \\
& & $\begin{array}{l}\text { Madrasah Ibtidaiyah } \\
\text { Toko mainan } \\
\end{array}$ \\
& & Perumahan \\
\hline
\end{tabular}

2. Solusi untuk masalah permodalan, mitra akan di beri pendidikan dan pelatihan dalam pembuatan laporan keuangan/ pembukuan; sehingga nantinya usaha mitra mudah dipantu perkembangannnya. Dengan luaran dan spesifikasi yang dihasilkan sebagai berikut:

\begin{tabular}{|l|l|l|}
\hline No & Luaran & Spesifikasi \\
\hline 1 & Laporan & Neraca \\
Keuangan & $\begin{array}{l}\text { Laporan laba/rugi } \\
\text { Laporan perubahan } \\
\text { modal }\end{array}$ \\
\hline
\end{tabular}

\section{METODE PELAKSANAAN}

Berdasarkan permasalahan yang telah di kemukakan, maka dalam kegiatan $\mathrm{I}_{\mathrm{b}} \mathrm{M}$ ini metode pelaksanaan yang ditawarkan untuk solusidari permasalahan mitra; adalah metode penyuluhan, pelatihan dan pendampingan;
Prosedur Kerja Untuk Mendukung Realisasi Program

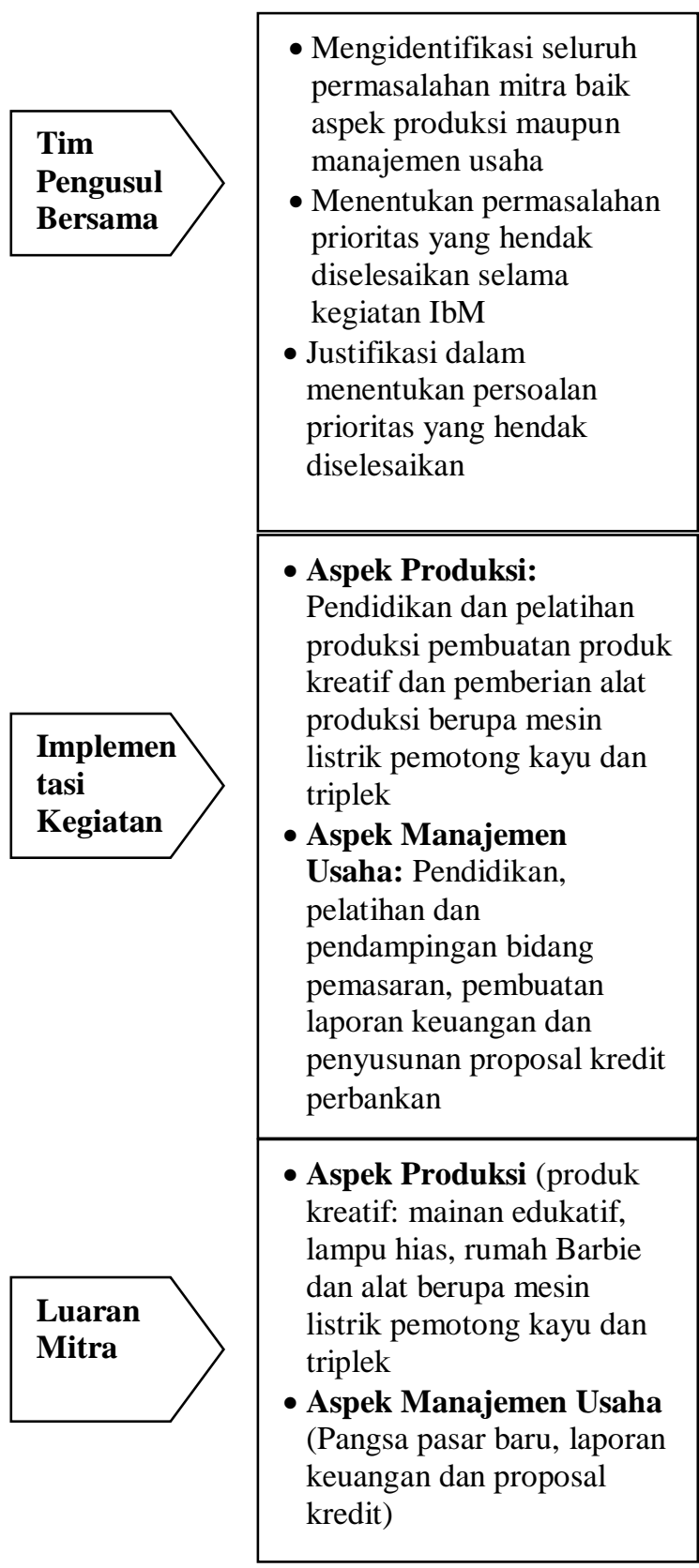

\section{DAMPAK}

TERSELESAIKANNYA PERMASALAHAN

YANG MENGHAMBAT PERKEMBANGAN

USAHA DAN TERCAPAINYA KEMANDIRIAN EKONOMI MITRA

Gambar 1. Prosedur Kerja

\section{KELAYAKAN PERGURUAN TINGGI}

\subsection{Kinerja LPM}

Lembaga Pengabdian Masyarakat Universitas Negeri Medan beserta staf, memberikan arahan dan bimbingan, sosialisasi pembuatan Proposal IbM, 
IbW, IbK, IbPE dan IbIKK kepada seluruh dosen di lingkungan Unimed, seminar proposal, dan seminar laporan akhir.

\subsection{Jenis Kepakaran}

Tim pengusul kegiatan IbM ini melibatkan berbagai disiplin ilmu, yang terdiri dari Dosen Jurusan manajemen Fakultas Ekonomi UNIMED, dosen jurusan administrasi perkantoran Fakultas Ekonomi Unimed, dan dosen jurusan seni rupa Fakultas Bahasa dan Seni Unimed yang telah memiliki pengalaman pengabdian kepada masyarakat terutama berkaitan dengan topik usaha kreatif dan manajemen usaha.

\section{HASIL YANG DICAPAI}

Hasil yang dicapai dalam pelaksanaan kegiatan pengabdian masyarakat ini adalah:

1. Mitra telah diberi peralatan berupa mesin potong triplek dan perlatan pendukung lain yang diperlukan untuk memudahkan proses produksi dan memperoleh hasil/kualitas yang lebih baik

2. Mitra telah diberi pelatihan serta pendampingan pembuatan produk kreatif berupa aneka permainan edukatif, lampu hias berbahan triplek dan mainan anak berupa rumah barbie yang jelas pangsa pasarnya dan memiliki nilai ekonomis yang tinggi

3. Sampai saat ini mitra sudah mampu memasarkan produknya (produk yang sudah laku terjual adalah rumah Barbie sebanyak 2 unit dengan harga jual Rp. 900.000/ unit $=$ Rp. 1.800.000, dengan keuntungan sebesar 60\% atau sekitarRp. 450.000/unit $=$ Rp . 900.000,) modal dibelanjakan kembali untuk pembelian bahan baku agar usaha dapat berkesinambungan.

4. Dari beberapa produk yang dihasilkan (mainan edukatif, lampu hias dan rumah barbie) ternyata yang paling diminati konsumen adalah rumah barbie, sehingga mitra lebih focus dalam memproduksinya.

Kendala yang dihadapi pada saat pelaksanaan kegiatan ini:

1. Terjadi perubahan kondisi dimana pada saat survey mitra 1 dan 2 menjalankan usaha pembuatan produk kreatif (lampu hias dan lemari pakaian) ketika kegiatan IbM ini dilaksanakan yang bersangkutan kurang focus dalam mengikuti kegiatan pelatihan, hal ini disebabkan mitra meliliki usaha baru yaitu usaha budidaya jamur tiram yang sudah dilakoninya sejak 6 bulan terakhir, menurutnya sekarang ini usaha jamur tiram lebih menjanjikan. Pada saat kegiatan IbM ini dilaksanakan; mitra mengirimkan satu anggotanya untuk mengikuti kegiatan pelatihan karena yang bersangkutan lagi sibuk membuat baglok/ media tanam jamur tiram pesanan dari pelanggan yang jumlahnya cukup banyak 30.000 baglog.

\section{KESIMPULAN DAN SARAN}

\subsection{Kesimpulan}

Desa Paya Pasir merupakan desa yang terletak di kecamatan tebing syahbandar kabupaten serdang bedagai, yang jaraknya $58 \mathrm{Km}$ dari Universitas negeri Medan; dan berjarak $20 \mathrm{Km}$ dari kota tebing tinggi didaerah ini mulai marak atau tumbuh bisnis properti (Perumahan dan Ruko khususnya di sepanjang jalan utama tebing tinggi kisaran dan sekitarnya ;memiliki potensi menghasilkan limbah kayu dan triplek bongkaran konstruksi beton yang jumlahnya cukup banyak dan belum dioptimalkan pemanfaatannya. Limbah kayu dan triplek ini masih dapat ditingkatkan nilainya dengan memanfaatkannya menjadi produk kreatif berupa permainan edukatif, lapion hias, rumah barbie dll yang bernilai jual tinggi dan jelas pangsa pasarnya.

Dari beberapa produk yang dihasilkan dari kegiatan IbM ini (mainan edukatif, lampu hias dan rumah barbie) ternyata yang paling diminati konsumen adalah rumah barbie, sehingga mitra lebih fokus dalam memproduksinya.

Mitra akan terus diberi pendampingan dalam mengelola usahanya sehingga berharap tujuan dari kegiatan ini tercapai sesuai dengan yang direncanakan.

\subsection{Saran}

1. Menangani permasalahan pelaku UMKM yang sangat kompleks, memerlukan kerjasama antara pemerintah, perguruan tinggi, Lembaga swadaya masyarakat dan para relawan lainnya.

2. Khusus untuk mitra program yang telah mendapatkan pelatihan dalam kegiatan IbM ini, harus lebih serius dalam menjalankan usaha dan mau melakukan apa yang telah disarankan oleh tim pengabdian agar lebih mudah diperoleh kemandirian dan kesejahteraan ekonomi sesuai yang di inginkan. 
LAMPIRAN

Poto Poto Kegiaytan Ibm Pembuatan Produk Kreatif Di Tebing Syahbandar
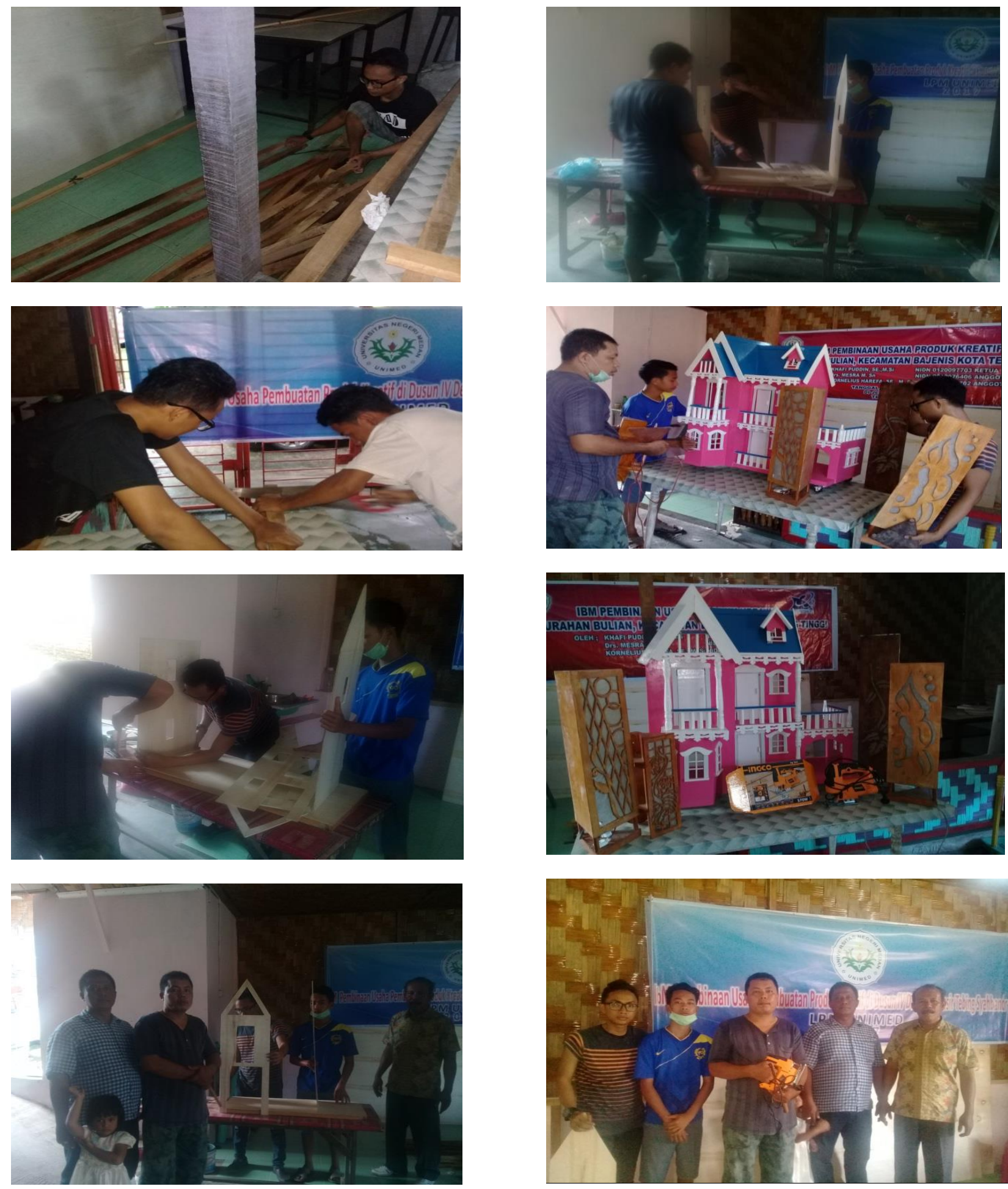

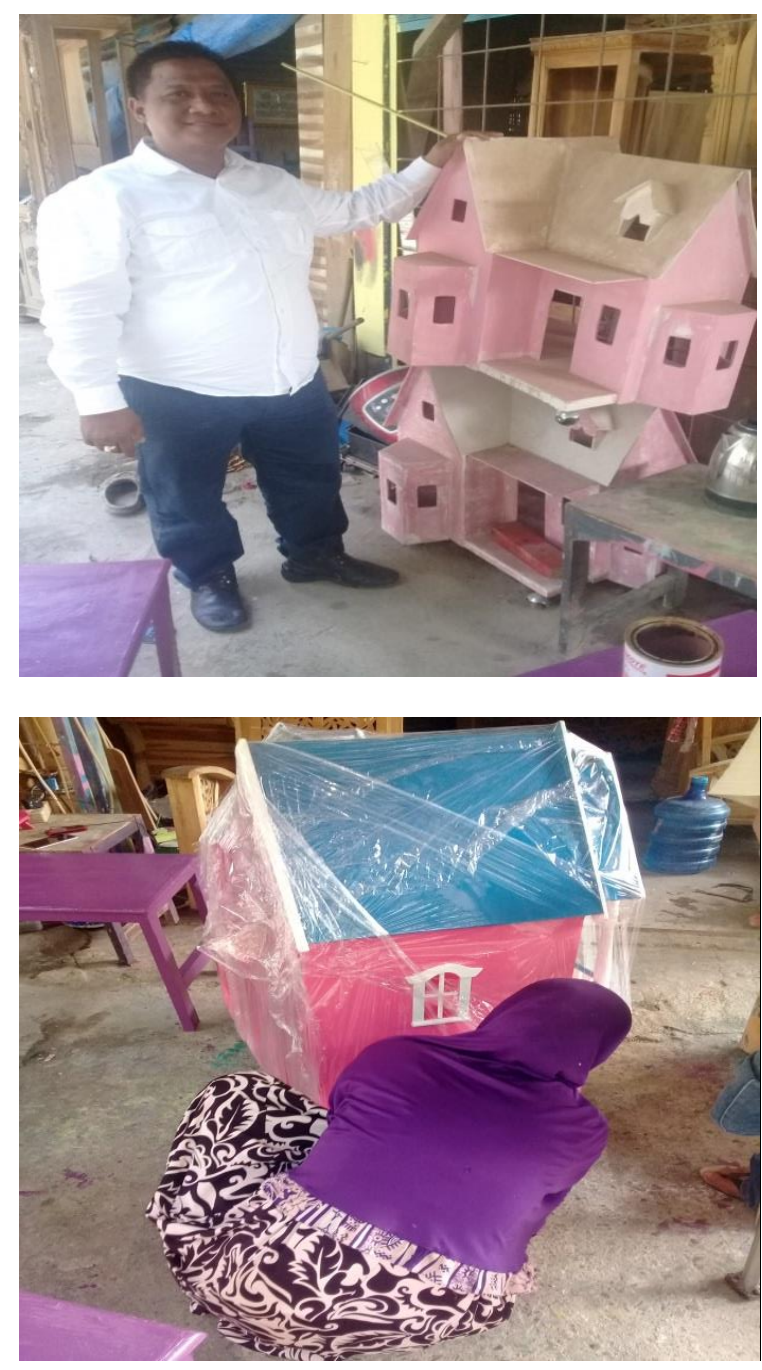
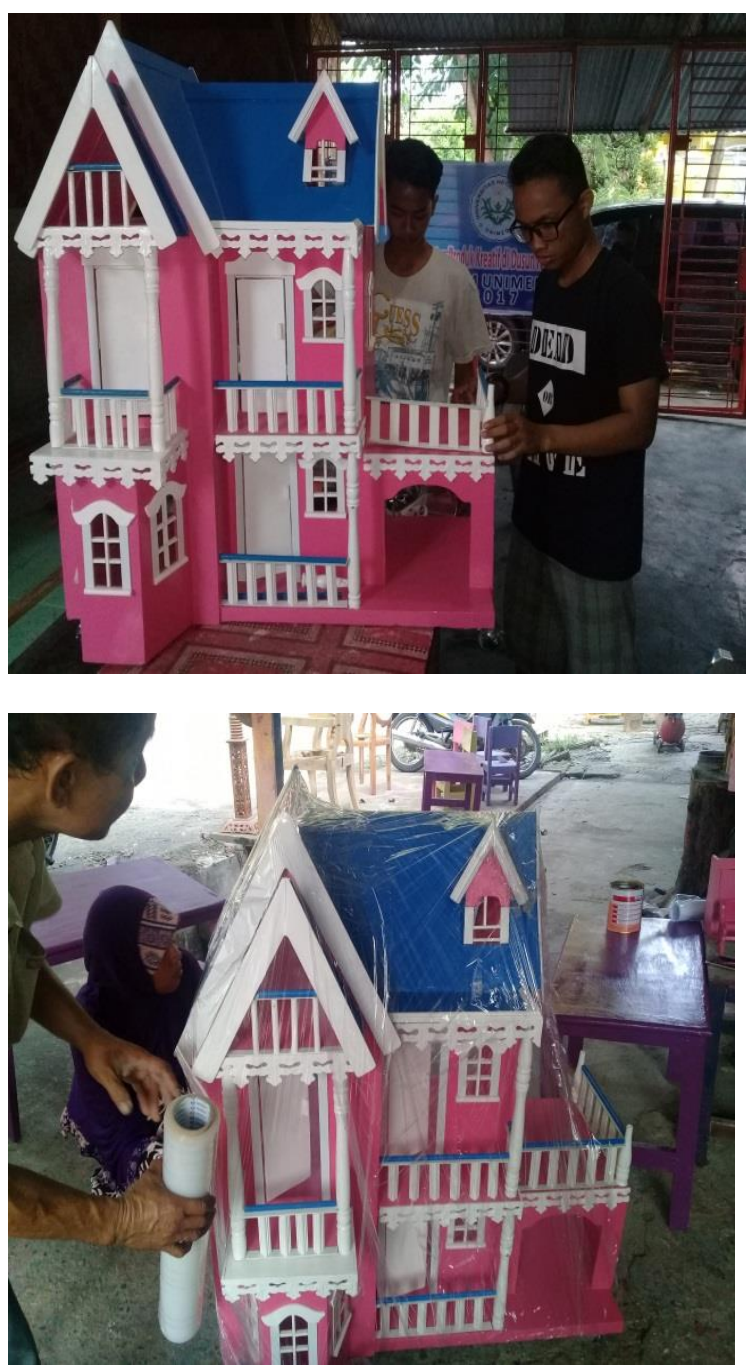